\title{
ASO Author Reflections: Non-radioactive Sentinel Node Localization with Superparamagnetic Iron Oxide in Clinically Node-Negative Breast Cancer Patients: A Possibility for Improvement of the Care Pathway
}

\author{
Maria Margarete Karsten, MD, Sina Shams (1), and Friedrich Kühn \\ Department of Gynecology, Corporate Member of Freie Universität Berlin, Humboldt-Universität zu Berlin and Berlin \\ Institute of Health, Charité-Universitätsmedizin Berlin, Berlin, Germany
}

\section{PAST}

Sentinel node biopsy (SNB) was first established in the therapy of early-stage melanoma, ${ }^{1}$ then subsequently adopted for other oncologic entities. Currently, it is a pivotal part of the staging and therapy for breast cancer patients. In this context, various agents for sentinel lymph node localization have proven suitable for reaching high detection rates and low false-negative rates. ${ }^{2}$ Radioactive localization using technetium ${ }^{99}\left(\mathrm{Tc}^{99}\right)$ in combination with blue dye or as a single tracer has long been considered the "gold standard." However due to the short half-life of technetium, injections need to be scheduled close to surgery. Radiation protection measures, and in Germany additional lymphoscintigraphy, are mandatory and extend the preparation time. A more flexible schedule and thus an increase in patient comfort might be achieved by using superparamagnetic iron oxide (SPIO). Proven equivalent to $\mathrm{Tc}^{99}$ for primary SNB by multiple meta-analyses, ${ }^{2},{ }^{3} \mathrm{SPIO}$ can be administered up to 7 days before surgery.

Maria Margarete Karsten and Sina Shams have contributed equally to this work.

(C) The Author(s) 2020

First Received: 22 October 2020

Accepted: 22 October 2020;

Published Online: 10 November 2020

M. M. Karsten, MD

e-mail: maria-margarete.karsten@charite.de

\section{PRESENT}

This study enrolled 59 patients at Charité-Universitätsmedizin Berlin to investigate the impact of SPIO use for SNB on the care process, reimbursement, surgical time, and patient comfort compared with ${ }^{99} \mathrm{Tc}^{4}$ The preoperative preparation time was significantly shorter for the SPIO group (SPIO, $5.4 \pm 1.3 \mathrm{~min}$ vs $\mathrm{TC}^{99}, \quad 82 \pm 20 \mathrm{~min}$; $p<0.0001$ ), even with omission of the time spent for lymphoscintigraphy ( $\mathrm{TC}^{99}, 54.4 \pm 13.6 \mathrm{~min} ; p<0.0001$ ). Also, the duration of the sentinel lymph node extraction was slightly shorter (SPIO, $5 \mathrm{~min}$ [range, 3-15 min] vs $\mathrm{TC}^{99}, 10$ min [range, $7-15 \mathrm{~min}$ ]; $p=0.151$ ). With SPIO, the duration of the whole SNB procedure also was shorter (SPIO, 9 min [range, 4-15 min] vs $\mathrm{TC}^{99}, 10 \mathrm{~min}$ [range, $7-15 \mathrm{~min}] ; p=0.412$ ) despite the fact that the iron-based system was a new method at our institution. Concerning pain assessment and reimbursement, the study could not detect any significant differences between the two groups. The study was limited by its small sample size, non-randomized group allocation, and variation in surgical procedures (mastectomy and breast-conserving surgery). In hindsight, detailed patient-reported experience measurements would have been favorable for examination of patient comfort.

\section{FUTURE}

The aforementioned findings show that SPIO-based sentinel-node localization facilitates a shortened preoperative preparation time and has no negative impact on reimbursement in the German health care setting. Due to a multitude of reasons such as lack of health care 
professionals, decreased financial resources, and development of even more complex therapy regimens, specialized oncologic care probably will be provided in fewer but larger centers, thus increasing travel time for patients and making scheduling of procedures even more critical. Flexible and less time-consuming alternatives to radioactive sentinel node-marking, such as the SPIO-guided approach, are necessary, especially in rural areas, where nuclear medicine facilities usually are scarce. Further studies should investigate the safety of SPIO for SNB after neoadjuvant chemotherapy (NACT). Currently, dual tracing with $\mathrm{TC}^{99}$ and blue dye is recommended in this context. In addition, the SPIO application method and dose for patients in need of postoperative magnetic resonance imaging (MRI) still need to be examined. ${ }^{5}$

FUNDING Open Access funding enabled and organized by Projekt DEAL.

DISCLOSURE Maria Margarete Karsten received a speaker's fee from SYSMEX Deutschland (Norderstedt, Germany). The remaining authors have no conflicts of interest.

OPEN ACCESS This article is licensed under a Creative Commons Attribution 4.0 International License, which permits use, sharing, adaptation, distribution and reproduction in any medium or format, as long as you give appropriate credit to the original author(s) and the source, provide a link to the Creative Commons licence, and indicate if changes were made. The images or other third party material in this article are included in the article's Creative Commons licence, unless indicated otherwise in a credit line to the material. If material is not included in the article's Creative Commons licence and your intended use is not permitted by statutory regulation or exceeds the permitted use, you will need to obtain permission directly from the copyright holder. To view a copy of this licence, visit http://creativecommons. org/licenses/by/4.0/.

\section{REFERENCES}

1. Morton DL, Wen DR, Wong JH, et al. Technical details of intraoperative lymphatic mapping for early-stage melanoma. Arch Surg. 1992;127:392-9.

2. Mok CW, Tan SM, Zheng Q, Shi L. Network meta-analysis of novel and conventional sentinel lymph node biopsy techniques in breast cancer. BJS Open. 2019;3:445-52.

3. Karakatsanis A, Christiansen PM, Fischer L, et al. The Nordic SentiMag trial: a comparison of super paramagnetic iron oxide (SPIO) nanoparticles versus $\mathrm{Tc}^{99}$ and patent blue in the detection of sentinel node $(\mathrm{SN})$ in patients with breast cancer and a metaanalysis of earlier studies. Breast Cancer Res Treat. 2016;157:281-94.

4. Shams S, Lippold K, Blohmer JU, Roehle R, Kühn F, Karsten MM. A pilot study evaluating the effects of Magtrace for sentinel node biopsy in breast cancer patients regarding care process optimization, reimbursement, surgical time, and patient comfort compared to standard technetium ${ }^{99}$. Ann Surg Oncol. 2020. http s://doi.org/10.1245/s10434-020-09280-1.

5. Karakatsanis A, Obondo C, Abdsaleh S, Hersi A-F, Eriksson S, Wärnberg F. Optimisation of breast MRI compatibility after sentinel node biopsy with paramagnetic tracers. Eur J Surg Oncol. 2018;44:731-2.

Publisher's Note Springer Nature remains neutral with regard to jurisdictional claims in published maps and institutional affiliations. 